\title{
Substance $P$ prevents 1-methyl-4-phenylpyridinium- induced cytotoxicity through inhibition of apoptosis via neurokinin-1 receptors in MES23.5 cells
}

\author{
SHUANG-YAN WANG ${ }^{1,2}$, LEI CHEN $^{1}$, YAN XUE $^{1}$ and YU-JUN XIA ${ }^{2}$ \\ Departments of ${ }^{1}$ Physiology and ${ }^{2}$ Anatomy, Qingdao University, Qingdao, Shandong 266071, P.R. China
}

Received September 22, 2014; Accepted August 25, 2015

DOI: $10.3892 / \mathrm{mmr} .2015 .4464$

\begin{abstract}
Sar $\left.{ }^{9}, \operatorname{Met}\left(\mathrm{O}_{2}\right)^{11}\right]$ termed Substance P (SP), is an effective and selective agonist for the neurokinin-1 (NK-1) receptors, which are synthetic peptides, similar in structure to SP. SP is an important neurotransmitter or neuromodulator mediated by neurokinin receptors, namely the SP receptor in the central nervous system. The excitatory effects induced by SP may be selectively inhibited by a neurokinin-1 receptor antagonist, such as SR140333B. It has been proposed that Parkinson's disease (PD) is primarily caused by the loss of trophic peptidergic neurotransmitter, possibly SP, which may lead to the degeneration of neurons. In previous studies, 1-methyl-4-phenylpyridinium $\left(\mathrm{MPP}^{+}\right)$has been frequently utilized to establish animal or cell models of PD. In the present study, to further investigate the effects of SP in PD, MPP ${ }^{+}$was employed to investigate the promising anti-apoptotic effects of $\mathrm{SP}$, and examine the underlying mechanisms of the pathology in the MES23.5 dopaminergic cell line. The results indicated that $\mathrm{MPP}^{+}$-triggered apoptosis was prevented by treatment with SP. SP treatment also decreased the $\mathrm{MPP}^{+}$-triggered $\mathrm{Ca}^{2+}$ influx, caspase-3 re-activity, reactive oxygen species production and mitochondrial membrane potential decrease. Treatment with $\mathrm{MPP}^{+}$also induced phosphorylation of c-Jun $\mathrm{N}$-terminal kinase and p38 mitogen-activated protein kinase. In addition, treatment with SP inhibited the $\mathrm{MPP}^{+}$-triggered neurotoxicity in MES23.5 cells. However, no changes were observed in SR140333B+SP+MPP+-treated MES23.5 cell lines. In conclusion, $\mathrm{SP}$ could protect the cells from $\mathrm{MPP}^{+}$-induced cytotoxicity by inhibiting the apoptosis via NK-1 receptors.
\end{abstract}

Correspondence to: Dr Lei Chen, Department of Physiology, Qingdao University, 308 Ning Xia Road, Qingdao, Shandong 266071, P.R. China

E-mail: chenleiqingd@yeah.net

Key words: Substance P, neuroprotection, c-Jun N-terminal kinase, 1-methyl-4-phenylpyridinium, Parkinson's disease

\section{Introduction}

Parkinson's disease (PD) is a serious degenerative disorder, which is the second most prevalent type of neurodegenerative disorder in humans, particularly in older individuals (1). A previous study demonstrated that PD is predominantly caused by the degeneration of dopaminergic neurons in the substantia nigra among other localizations (2); however, the specific cause of the cell death remains to be elucidated. Former studies involving PD models and clinical patients have identified two main cell death pathways, including the autophagy pathway and the intrinsic or extrinsic apoptosis pathway (3-5). Human postmortem studies also found that dopaminergic neuronal death is caused by apoptosis in patients with PD $(6,7)$. Fas receptor (8) and autophagic vacuole (9) levels were observed to be increased in patients with PD and PD experimental models (10). Increasing evidence supports the hypothesis that apoptosis is important in the death of cells and degeneration of the neurons in PD. 1-Methyl-4-phenylpyridinium $\left(\mathrm{MPP}^{+}\right)$is a potential neuronal toxin, which induces the degeneration of nigrostriatal neurons in rodents and primates $(6,10)$. Therefore, $\mathrm{MPP}^{+}$has been used in numerous studies to establish models of PD $(6,10,11)$.

$\left[\operatorname{Sar}^{9}, \operatorname{Met}\left(\mathrm{O}_{2}\right)^{11}\right]$ termed Substance P (SP), is a widely distributed undecapeptide, which is considered to be a neurotransmitter or neuromodulator $(12,13)$ in the human central nervous system (CNS). By interacting with the neurokinin-1 (NK-1) receptors, SP is able to effectively regulate neuronal activity in a few localizations in the brain. Thornton and Vink (14) demonstrated that SP is involved in certain neurological diseases, such as PD and Alzheimer's disease (AD). The electrophysiological studies of Nalivaiko et al (15) revealed that SP could effectively regulate nigral dopaminergic neurons (15). Strell et al (16) reported that SP could enhance dopamine release from the striatal dopamine terminals in the brain (16). Thus, dopamine may be involved in maintaining the integrity of the neuronal population (13).

In the present study, neuronal cultures were treated with $\mathrm{MPP}^{+}$to induce a model, and were analyzed to evaluate the $\mathrm{Ca}^{2+}$ influx level, the caspase-3 activity, the level of reactive oxygen species (ROS) and the mitochondrial membrane potential $(\Delta \psi \mathrm{m})$. The p38 mitogen-activated protein kinase (MAPK) kinase and c-Jun N-terminal kinase (JNK) levels were detected using western blotting. To investigate the 
protective effects of SP, the cells were pretreated with SP prior to exposure to $\mathrm{MPP}^{+}$. For the NK-1 receptor inhibitor (SR) antagonism, the cells were pretreated with SR prior to treatment with SP. For the MAPK inhibitor treatment, the cells were treated with JNK-specific inhibitor (SP600125) and p38-specific inhibitor (SB203580) prior to exposure to $\mathrm{MPP}^{+}$ The aim of the present study was to investigate whether SP could protect the dopaminergic neurons from $\mathrm{MPP}^{+}$-triggered neurotoxicity, and to examine the anti-apoptotic mechanism.

\section{Materials and methods}

Materials. Skimmed milk sucrose peptone was purchased from Tocris Bioscience (Avonmouth, UK). The inhibitor, SR140333B, was provided by Sanofi-Aventis (Chilly-Mazarin, France). Dulbecco's modified Eagle's medium (DMEM)/F12 was purchased from Gibco Life Technologies (Grand Island, NY, USA). The commercial phycoerythrin (PE)-conjugated anti-caspase-3 monoclonal antibody kit was purchased from BD Pharmingen (San Diego, CA, USA). The Hoechst 33258 staining kit was purchased from Beyotime Institute of Biotechnology (Haimen, China). Fluo-3/AM were purchased from Molecular Probes Life Technologies (Carlsbad, CA, USA). Rabbit anti-phospho-P ${ }^{38}$ MAPK polyclonal antibody was purchased from Santa Cruz Biotechnology, Inc. (Dallas, TX, USA). Rabbit anti-rat phospho-JNK polyclonal antibody and mouse anti-rat phospho-c-Jun monoclonal antibody were purchased from Cell Signaling Technology, Inc. (Danvers, MA, USA). Horseradish peroxidase (HRP)-IgG was purchased from Pierce Biotechnology, Inc. (Rockford, IL, USA). SB20358 and SP600125 were purchased from Molecular Probes Life Technologies. The other reagents were of the highest grade and the other kits were purchased from local commercial companies.

Cell culture. Dopaminergic MES23.5 cells were obtained from Dr Wei-Dong Le (Qingdao University, Qingdao, China). MES23.5 cells exhibit certain properties, which are similar to those of primary neurons (17). Cells were cultured in DMEM/F12, which was supplemented with the $5 \%$ fetal bovine serum, $100 \mathrm{U} / \mathrm{ml}$ penicillin and $100 \mathrm{mg} / \mathrm{ml}$ streptomycin (Sigma-Aldrich, St. Louis, MO, USA) in a humid $5 \% \mathrm{CO}_{2}$ environment at $37^{\circ} \mathrm{C}$. The cells were seeded at a final density of $1 \times 10^{5} / \mathrm{cm}^{2}$ in the plates. When the confluence reached $70-80 \%$, the MES23.5 cells were treated with SP (at a final concentration of $10^{-7} \mathrm{~mol} / \mathrm{l}$ ) and SR (at a final concentration of $10^{-5} \mathrm{~mol} / \mathrm{l}$ ) alone or in combination for $24 \mathrm{~h}$. Subsequently, the cells were incubated with $\mathrm{MPP}^{+}(200 \mu \mathrm{mol} / \mathrm{l})$ for $24 \mathrm{~h}$ at room temperature (18).

MTT assay. MES23.5 cells were seeded and cultured in the 96-well plates at a cell density of $2 \times 10^{4}$ cells/well. Following cell attachment, the cells were incubated with different doses of SP or SR for $24 \mathrm{~h}$, with freshly prepared stock solutions. Subsequently, the $\mathrm{MPP}^{+}(200 \mu \mathrm{mol} / \mathrm{l})$ was added into the DMEM/F12 medium and serum deprivation was conducted for the subsequent $24 \mathrm{~h}$. Subsequently, the MES23.5 cells were incubated in MTT $(5 \mathrm{mg} / \mathrm{ml})$ for $4 \mathrm{~h}$ at room temperature, and cell injury was observed using a colorimetric assay (cat. no. ab39401; Abcam, Cambridge, UK).
Hoechst 33258 staining. The nuclear morphology of the cells was evaluated using a previously described method (19). Briefly, the cells were fixed, then washed twice with phosphate-buffered saline solution. Subsequently, the cells were stained with Hoechst 33258 staining solution. The apoptotic cells were determined by the following features: Nuclear morphology changes, chromatin condensation and chromatin fragmentation. Briefly, the quantity of the condensed cells was counted manually by investigators using a fluorescence microscope (BX51; Olympus Corporation, Tokyo, Japan) (20). The specific methods of the experiments were performed according to those of a previous study (19). The data are expressed as the percentage of condensed nuclei compared with the total cell number.

Assay of activated caspase-3. The caspase- 3 activity was evaluated according to the manufacturer's instructions (BD Pharmingen). The cells were washed with cold PBS twice, and resuspended in Cytofix/Cytoperm ${ }^{\mathrm{TM}}$ solution (final concentration, $1 \times 10^{6}$ cells $/ 0.5 \mathrm{ml}$; (BD Biosciences, San Jose, CA, USA). The cells were incubated on ice for $20 \mathrm{~min}$, and were washed with Perm/wash buffer twice. Subsequently, the cells were incubated with antibodies in the Perm/wash buffer (1:5). Following washing with Perm/wash buffer, the cells were resuspended with $0.5 \mathrm{ml} \mathrm{Perm} /$ wash buffer, incubated with CD8-PE (BD Biosciences) at $37^{\circ} \mathrm{C}$ and analyzed using a flow cytometric assay (FC500; Beckman Coulter, Inc., Brea, CA, USA). The apoptosis level was evaluated by counting the caspase-3-positive cells as a percentage of total MES23.5 cells using CellQuest software (version 2.0; BD Biosciences).

Examination of $\Delta \psi m$. The $\Delta \psi \mathrm{m}$ of MES23.5 cells was examined by staining with rhodamine 123 (Sigma-Aldrich), and observed using flow cytometry (BD Biosciences). The rhodamine 123 staining and flow cytometric observations were performed according to previously described methods $(21,22)$. The cells in different groups were incubated with $100 \mu \mathrm{mol} / 1$ ferrous iron $(\mathrm{pH}, 6.0)$ for $3 \mathrm{~h}$ at room temperature. Subsequently, the cells were incubated with rhodamine $123(5 \mu \mathrm{mol} / \mathrm{l})$ at $37^{\circ} \mathrm{C}$ for $30 \mathrm{~min}$. The cells were washed twice with HEPES-buffered saline, and the fluorescence was observed at wavelengths of $488 \mathrm{~nm}$ excitation and $525 \mathrm{~nm}$ emission using an inverted fluorescence microscope (IX3; Olympus Corporation).

ROS detection. The intracellular levels of ROS were detected using 2',7'-dichlorodihydrofluorescein diacetate $\left(\mathrm{H}_{2} \mathrm{DCFDA}\right.$; Sigma-Aldrich) according to a previously described method (23). The cells were washed with PBS three times, and were incubated with DMEM/F12 containing $\mathrm{H}_{2}$ DCFDA (10 $\mu \mathrm{mol} / \mathrm{l})$ for $30 \mathrm{~min}$. Finally, the fluorescence signals of the cells were observed at wavelengths of excitation of $488 \mathrm{~nm}$ and emission of $525 \mathrm{~nm}$.

Evaluation of intracellular $\mathrm{Ca}^{2+}$. In the present study, intracellular free $\mathrm{Ca}^{2+},\left[\mathrm{Ca}^{2+}\right]_{\mathrm{i}}$, was evaluated using Invitrogen Fluo-3/AM (Thermo Fisher Scientific, Inc., Waltham, MA, USA) according to a previously described method (24). The cells were harvested and centrifuged at a speed of $1,000 \mathrm{x}$ g for $5 \mathrm{~min}$, then treated with Fluo-3/AM $(10 \mu \mathrm{M})$ in serum-free DMEM for $30 \mathrm{~min}$ at $37^{\circ} \mathrm{C}$. The cells were analyzed and observed using the $\mathrm{BD}$ 


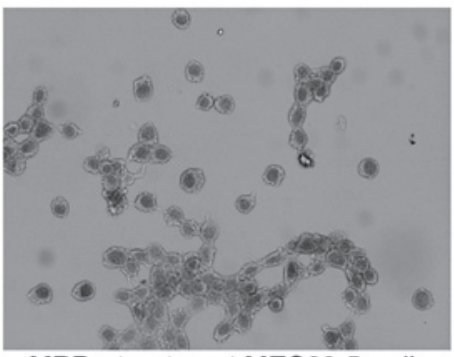

MPP+-treatment MES23.5 cells

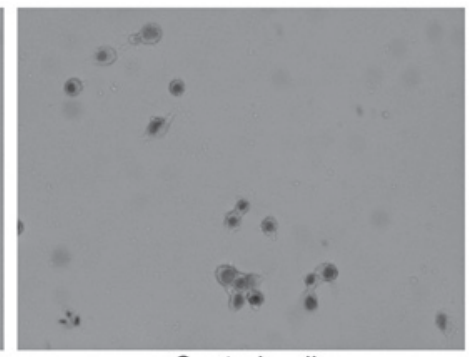

Control cells

Figure 1. Widespread labeling of cell bodies immunopositive for neurokinin-1, compared with the control. The images were stained using the anti-neurokinin-1 protein antibody (magnification, x100). $\mathrm{MPP}^{+}, 1$-methyl-4-phenylpyridinium.

Biosciences FACS Calibur flow cytometer (for Fluo-3) (25). For each experiment, $10 \mathrm{nM}$ digitonin (Sigma-Aldrich) or $2 \mu \mathrm{M}$ ionomycin (Sigma-Aldrich) was used to treat the cells at the end of the experiments, resulting in maximal fluorescence of Fura-2 and Fluo-3, respectively. Finally, the minimal fluorescence was evaluated by addition of $5 \mathrm{mM}$ EGTA.

Western blot analysis. The cells were harvested and lysed in lysis buffer [50 mM Tris- $\mathrm{HCl}(\mathrm{pH} 7.4), 150 \mathrm{mM} \mathrm{NaCl}, 1 \%$ Nonidet P-40, $1 \mathrm{mM}$ EDTA, $10 \mu \mathrm{g} / \mathrm{ml}$ aprotinin and $1 \mathrm{mM}$ phenylmethylsulfonyl fluoride]. The nuclear and cytoplasmic proteins were extracted and isolated as described in a previous study by Wang et al (26). The nuclear and cytoplasmic proteins were isolated using the Nuclear and Cytoplasmic Protein Extraction kit (Beyotime Institute of Biotechnology). The final concentration of the proteins was examined using a Bradford assay kit (Bio-Rad Laboratories, Inc., Hercules, CA, USA). The proteins were separated with $10 \%$ SDS-PAGE (Tiangen Biotech (Beijing) Co., Ltd., Beijing, China), and then transferred to the polyvinylidene difluoride membranes (Tiangen Biotech (Beijing) Co., Ltd.) for detection. The membranes were blocked with 5\% non-fat milk at room temperature overnight, and then treated with a rabbit anti-rat phospho-P38 monoclonal antibody (1:3,000; cat. no. Sc-7975-R; Santa Cruz Biotechnology, Inc.), rabbit anti-rat phospho-JNK polyclonal antibody (1:3,000; cat. no. Sc-135642; Santa Cruz Biotechnology, Inc.) and rabbit antirat phospho-c-Jun polyclonal antibody (1:2,000; cat. no. 3270; Cell Signaling Technology, Inc.), respectively overnight at $4^{\circ} \mathrm{C}$. Subsequently, the membranes were incubated with the goat anti-rabbit polyclonal antibodies conjugated with HRP-IgG at a dilution of 1:200 (cat. no. A27033; Pierce Biotechnology, Inc.). The cross-reactivity of proteins was visualized using enhanced chemiluminescence reagents (Pierce Biotechnology, Inc.), and then analyzed via scanning densitometry using the Tanon Image system (Tanon Science \& Technology Co., Ltd., Shanghai, China).

Statistical analysis. All data in the present study were analyzed using SPSS software version 19.0 (SPSS, Inc., Armonk, NY, USA). The results are presented as the mean \pm standard error of the mean. Each experiment was performed at least three times, and the results were observed by at least three observers. One-way analysis of variance followed by the Student-Newman-Keuls test was utilized to compare the differences between the two groups. $\mathrm{P}<0.05$ was considered to indicate a statistically significant difference.
Table I. Changes in cell viability with different doses of SP treatment.

\begin{tabular}{lc}
\hline Group & MTT $(\%$ of control $)$ \\
\hline Control & $100.00 \pm 3.86$ \\
MPP $^{+}$ & $87.05 \pm 4.2^{\mathrm{a}}$ \\
$\mathrm{SP}\left(10^{-9} \mathrm{M}\right)+\mathrm{MPP}^{+}$ & $90.54 \pm 3.72^{\mathrm{a}, \mathrm{b}}$ \\
$\mathrm{SP}\left(10^{-8} \mathrm{M}+\mathrm{MPP}^{+}\right.$ & $91.18 \pm 3.53^{\mathrm{a}, \mathrm{b}}$ \\
$\mathrm{SP}\left(10^{-7} \mathrm{M}\right)+\mathrm{MPP}^{+}$ & $95.03 \pm 4.73^{\mathrm{a}, \mathrm{b}}$ \\
$\mathrm{SP}\left(10^{-6} \mathrm{M}\right)+\mathrm{MPP}^{+}$ & $93.61 \pm 5.05^{\mathrm{a}, \mathrm{b}}$ \\
$\mathrm{SP}\left(10^{-5} \mathrm{M}\right)+\mathrm{MPP}^{+}$ & $91.96 \pm 4.02^{\mathrm{a}, \mathrm{b}}$ \\
\hline
\end{tabular}

$\mathrm{F}=16.86$. Data are expressed as the mean \pm standard error of the mean. ${ }^{\mathrm{a}} \mathrm{P}<0.05$, compared with control; ${ }^{\mathrm{b}} \mathrm{P}<0.05$, compared with the $\mathrm{MPP}^{+}$-treated group. SP, substance $\mathrm{P} ; \mathrm{MPP}^{+}$, 1-methyl-4-phenylpyridinium; F, homogeneity test of variance.

Table II. Changes in cell viability with different doses of SR treatment.

\begin{tabular}{lc}
\hline Group & MTT $(\%$ of control $)$ \\
\hline Control & $100.00 \pm 1.33$ \\
MPP $^{+}$ & $85.01 \pm 1.62^{\mathrm{a}}$ \\
$\mathrm{SP}\left(10^{-7} \mathrm{M}\right)+\mathrm{MPP}^{+}$ & $90.06 \pm 1.36^{\mathrm{a}}$ \\
$\mathrm{SR}\left(10^{-6} \mathrm{M}\right)+\mathrm{SP}\left(10^{-7} \mathrm{M}\right)+\mathrm{MPP}^{+}$ & $84.94 \pm 1.74^{\mathrm{a}}$ \\
$\mathrm{SR}\left(10^{-5} \mathrm{M}\right)+\mathrm{SP}\left(10^{-7} \mathrm{M}\right)+\mathrm{MPP}^{+}$ & $82.54 \pm 1.81^{\mathrm{a}, \mathrm{b}}$ \\
$\mathrm{SR}\left(10^{-4} \mathrm{M}\right)+\mathrm{SP}\left(10^{-7} \mathrm{M}\right)+\mathrm{MPP}^{+}$ & $81.49 \pm 1.64^{\mathrm{a}, \mathrm{b}}$ \\
\hline
\end{tabular}

$\mathrm{F}=4.06$. Data are expressed as the mean \pm standard error of the mean. ${ }^{a} \mathrm{P}<0.05$, compared with the control; ${ }^{b} \mathrm{P}<0.05$ compared with the SP $\left(10^{-7} \mathrm{M}\right)+\mathrm{MPP}^{+}$treated group. SP, substance $\mathrm{P} ; \mathrm{MPP}^{+}$, 1-methyl-4-phenylpyridinium; SR, NK-1 receptor inhibitor; F, homogeneity test of variance.

\section{Results}

Immunohistochemistry. There are three subtypes of neurokinin receptors, including NK-1, NK-2, and NK-3. The NKs have selective affinities for SP, NKA, and NKB, respectively. It was identified that the MES23.5 cells bear positive NK-1 expression (Fig. 1). 
A

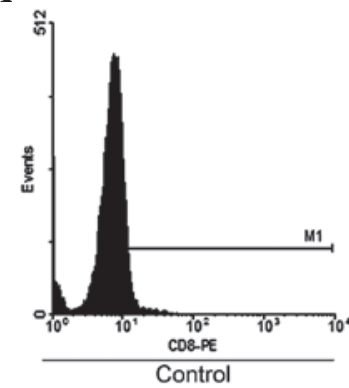

D

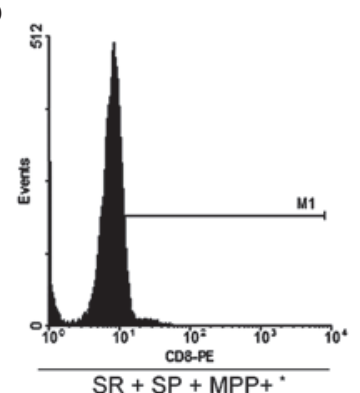

B

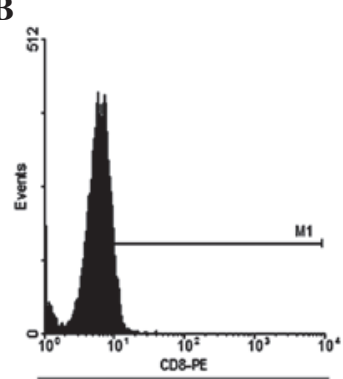

$\mathbf{E}$

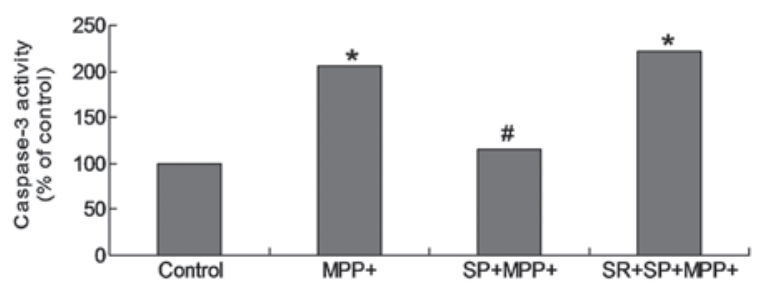

C

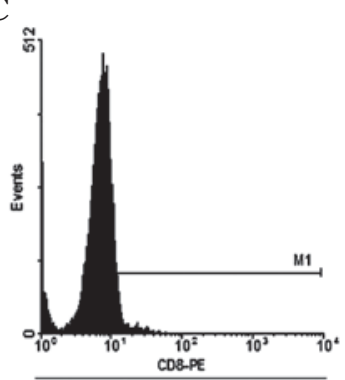

$\mathrm{SP}+\mathrm{MPP}+\#$

Figure 2. Caspase-3 activity decreases in $\mathrm{MPP}^{+}$-treated MES23.5 cells after incubation with SP for $24 \mathrm{~h}$. Representative data of the fluorometric assay of the (A) control group; (B) $\mathrm{MPP}^{+}$group; (C) $\mathrm{SP}+\mathrm{MPP}^{+}$group; and (D) $\mathrm{SR}+\mathrm{SP}+\mathrm{MPP}^{+}$group. (E) Statistical analysis of the data. Activated caspase-3 levels in the $\mathrm{SP}+\mathrm{MPP}^{+}$group were lower than that in the $\mathrm{MPP}^{+}$and $\mathrm{SR}+\mathrm{SP}+\mathrm{MPP}^{+}$groups. Data are expressed as the mean \pm standard error of the mean. "P<0.05, compared with control; ${ }^{\mathrm{P}} \mathrm{P}<0.05$, compared with $\mathrm{MPP}^{+}$group. $\mathrm{MPP}^{+}$, 1-methyl-4-phenylpyridinium; SP, substance P; SR, NK-1 receptor inhibitor.

A

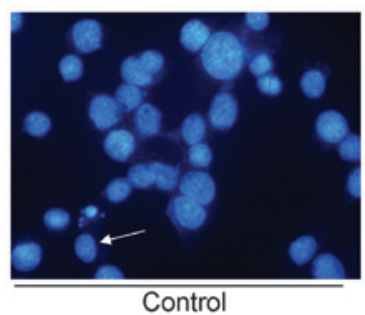

D

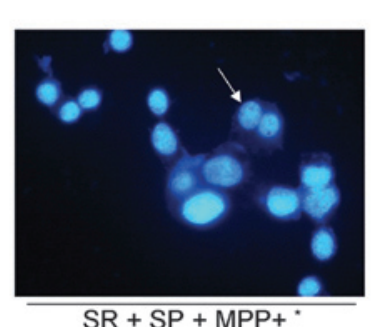

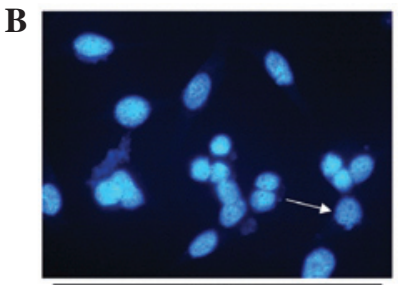

$\mathrm{MPP}^{+*}$

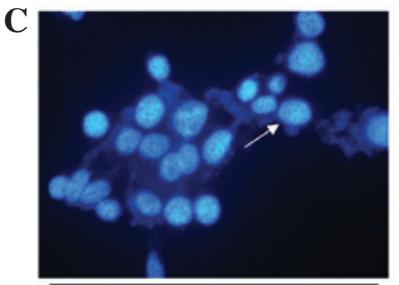

$\mathrm{SP}+\mathrm{MPP}+\#$

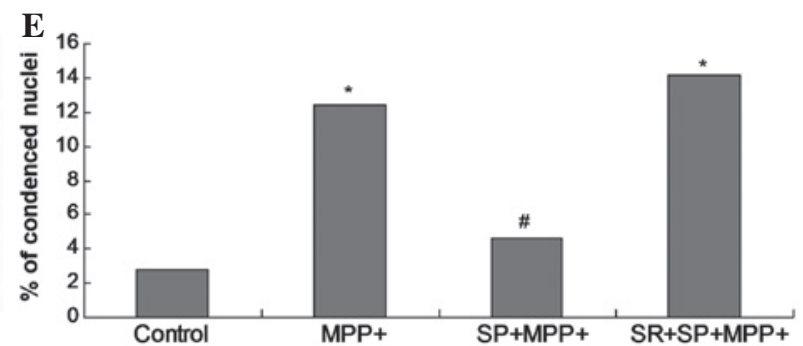

Figure 3. Morphological changes observed in the nuclei. Images of Hoechst staining in the (A) control group, (B) $\mathrm{MPP}^{+}$group, $(\mathrm{C}) \mathrm{SP}_{+} \mathrm{MPP}^{+}$group and (D) $\mathrm{SR}+\mathrm{SP}+\mathrm{MPP}^{+}$group. (E) Statistical analysis of condensed nuclei in different groups. In the control and SP groups, nuclei appeared with regular contours and were round and large in size. However, the nuclei of the $\mathrm{MPP}^{+}$and $\mathrm{SR}+\mathrm{SP}+\mathrm{MPP}^{+}$groups appeared hypercondensed (brightly stained) and exhibited fragmented chromatin. Magnification, $\mathrm{x} 400$. Data are expressed as the mean \pm standard error of the mean. ${ }^{\mathrm{P}}<0.05$, compared with control; ${ }^{\#} \mathrm{P}<0.05$, compared with $\mathrm{MPP}^{+}$group. $\mathrm{MPP}^{+}$, 1-methyl-4-phenylpyridinium; SP, substance P; SR, NK-1 receptor inhibitor.

Cell viability of $\mathrm{MPP}^{+}$-treated MES23.5 cells. In order to investigate whether SP exerted a protective effect on $\mathrm{MPP}^{+}$-treated MES23.5 cells, different doses of SP/SR alone and in combination were added to the culture medium. When pretreated with $10^{-9}-10^{-5} \mathrm{~mol} / 1 \mathrm{SP}$ for $24 \mathrm{~h}$, the cell viability was significantly increased compared with that of the untreated cells (Table I). However, no significant differences were identified in cell viability among the pretreatment with SP $\left(10^{-7} \mathrm{~mol} / \mathrm{l}\right)+\mathrm{SR}\left(10^{-6} \mathrm{~mol} / \mathrm{l}\right), \mathrm{SP}\left(10^{-7} \mathrm{~mol} / \mathrm{l}\right)+\mathrm{SR}$ $\left(10^{-5} \mathrm{~mol} / \mathrm{l}\right)$ and SP $\left(10^{-7} \mathrm{~mol} / \mathrm{l}\right)+\mathrm{SR}\left(10^{-4} \mathrm{~mol} / \mathrm{l}\right)$ groups for 24 h (Table II).
As shown in Table I and Table II, pretreatment with SP $\left(10^{-7} \mathrm{~mol} / \mathrm{l}\right)$ for $24 \mathrm{~h}$ is able to significantly increase the viability of the cells treated with $\mathrm{MPP}^{+}$. Therefore, SP $\left(10^{-7} \mathrm{~mol} / \mathrm{l}\right)$ was selected to perform the following experiments. As treatment with $10^{-5}-10^{-4} \mathrm{~mol} / \mathrm{l}$ SR140333B significantly inhibited the cell viability compared with the $\mathrm{SP}\left(10^{-7} \mathrm{M}\right)+\mathrm{MPP}^{+}$treated group, therefore, $10^{-5} \mathrm{~mol} / 1 \mathrm{SR} 140333 \mathrm{~B}$ was selected for the following experiments.

SP inhibits caspase-3 activation in MPP ${ }^{+}$-treated MES23.5 cells. According to a previous study, caspase- 3 is a critical protein in 
A

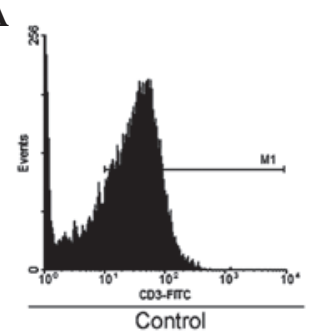

D

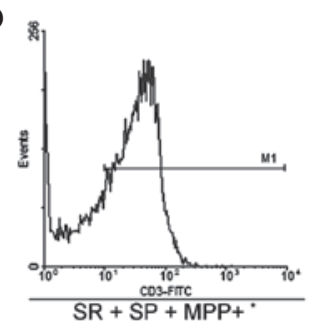

B

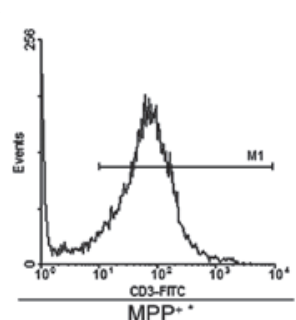

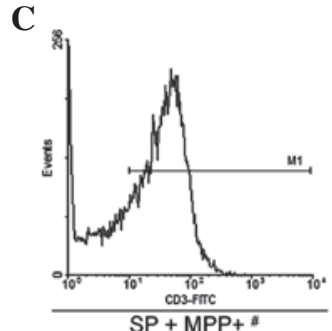

$\mathbf{E}$

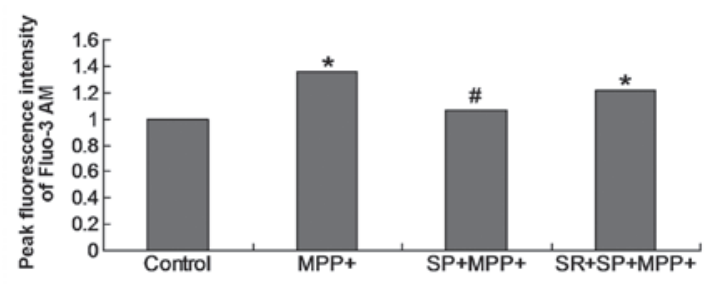

Figure 4. Intracellular $\mathrm{Ca}^{2+}$ level changes in the mitochondrial membrane. Intracellular $\mathrm{Ca}^{2+}$ levels in the (A) control group, (B) $\mathrm{MPP}{ }^{+}$group, (C) $\mathrm{SP}+\mathrm{MPP}{ }^{+}$group and (D) SR + SP + MPP ${ }^{+}$group. (E) Statistical analysis of the data. MPP ${ }^{+}$and $\mathrm{SR}+\mathrm{SP}+\mathrm{MPP}^{+}$increased the calcium influx in MES23.5 cells compared with the control, SP decreased the calcium influx in MES23.5 cells compared with the MPP ${ }^{+}$group, Data are expressed as the mean \pm standard error of the mean. ${ }^{*}<0.05$, compared with control; " $\mathrm{P}<0.05$, compared with $\mathrm{MPP}^{+}$group. $\mathrm{MPP}^{+}$, 1-methyl-4-phenylpyridinium; SP, substance P; SR, NK-1 receptor inhibitor.

A

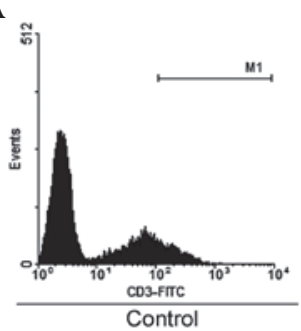

D

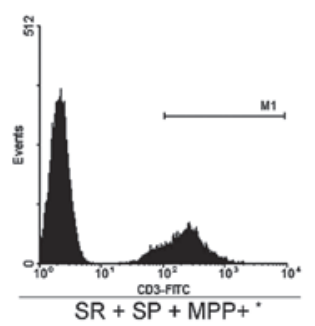

B

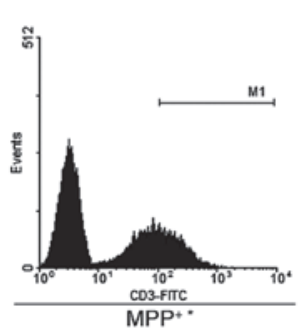

$\mathbf{E}$

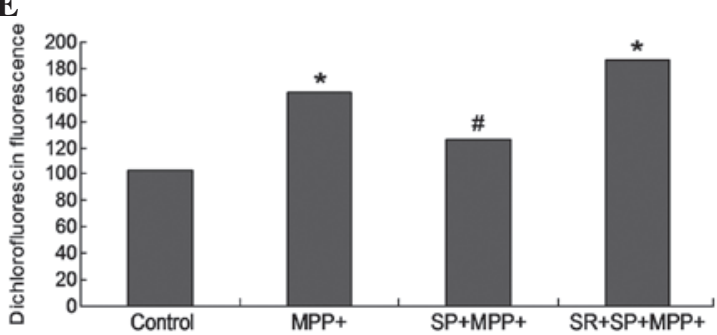

Figure 5. ROS production was decreased in MPP ${ }^{+}$-treated MES23.5 cells after SP incubation for $24 \mathrm{~h}$. The fluorometric assay in the (A) control group, (B) MPP ${ }^{+}$ group, (C) $\mathrm{SP}+\mathrm{MPP}^{+}$group and (D) $\mathrm{SR}+\mathrm{SP}+\mathrm{MPP}^{+}$group. (E) Statistical analysis of the data. $\mathrm{MPP}^{+}$and $\mathrm{SR}+\mathrm{SP}+\mathrm{MPP}$ increased the production of ROS

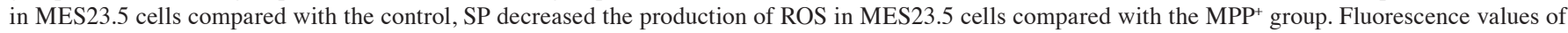
the control were set to $100 \%$. Data are expressed as the mean \pm standard error of the mean of six independent experiments. "P<0.05, compared with the control ${ }^{\sharp} \mathrm{P}<0.05$, compared with the $\mathrm{MPP}^{+}$group. ROS, reactive oxygen species; $\mathrm{MPP}^{+}, 1$-methyl-4-phenylpyridinium; SP, substance P; SR, NK-1 receptor inhibitor.

cell death and the apoptotic process. In the present study, active caspase-3 was detected using the PE-conjugated caspase-3 monoclonal antibody apoptosis kit (Fig. 2). The results indicate that the caspase- 3 activity in the $\mathrm{MPP}^{+}$and $\mathrm{SR}+\mathrm{SP}+\mathrm{MPP}^{+}$ groups was significantly higher when compared with the control group (Fig. 2; $\mathrm{P}<0.05$ ). Meanwhile, the caspase-3 activity was significantly decreased in the $\mathrm{SP}+\mathrm{MPP}^{+}$group as compared with the $\mathrm{MPP}^{+}$group $(\mathrm{P}<0.05)$. Furthermore, SR treatment may have increased the caspase- 3 activity significantly, when compared with the $\mathrm{SP}+\mathrm{MPP}^{+}$group alone (Fig. 2 ; $\mathrm{P}<0.05$ ).

SP antagonizes DNA fragmentation in the $\mathrm{MPP}^{+}$-treated MES23.5 cells. In order to further confirm the protective effect of SP on $\mathrm{MPP}^{+}$-treated MES23.5 cells, the nuclear morphology was analyzed using blue Hoechst 33258 (Fig. 3). The results demonstrate significantly increased quantities of DNA fragmentation and condensed nuclei in the $\mathrm{MPP}^{+}$group when compared with the control group (Fig. 3; $\mathrm{P}<0.05$ ). Treatment with SP may abrogate the increased quantities of DNA fragmentation and condensed nuclei, as the quantity of condensed nuclei in the $\mathrm{SP}+\mathrm{MPP}^{+}$group was significantly decreased when compared with that of the $\mathrm{MPP}^{+}$group $(\mathrm{P}<0.05)$.

SP inhibits calcium influx in $\mathrm{MPP}^{+}$-treated MES23.5 cells. $\left[\mathrm{Ca}^{2+}\right]_{\mathrm{i}}$ is important in specific cell events, such as cell apoptosis, cell death and other processes. The $\mathrm{Ca}^{2+}$ influx 


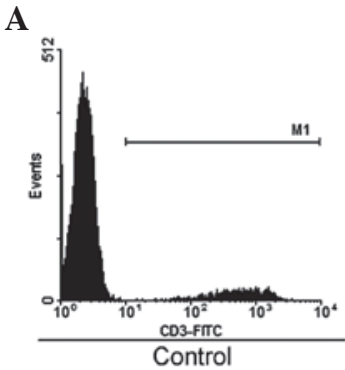

B

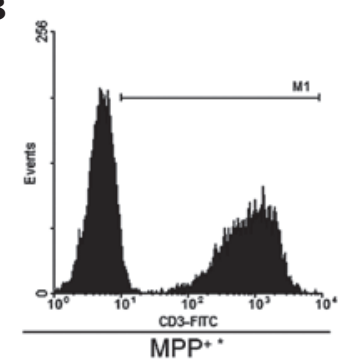

C

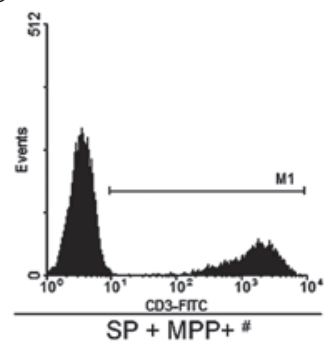

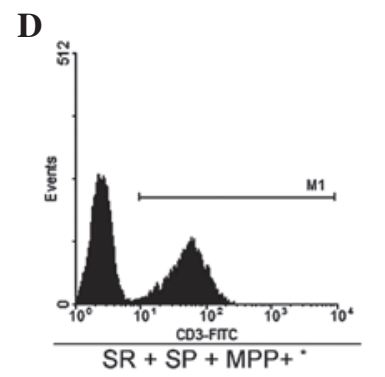

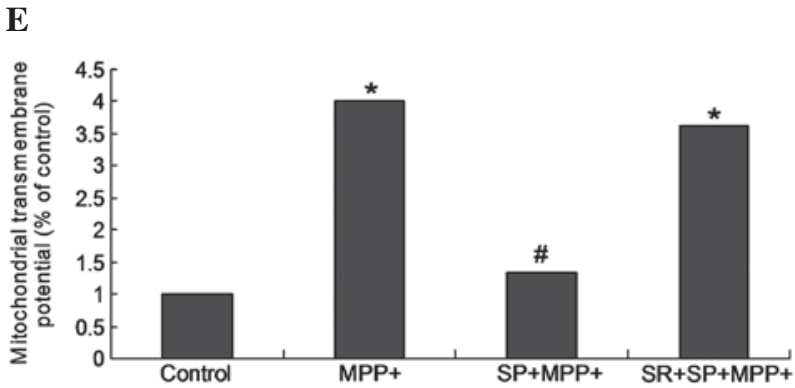

Figure 6. $\Delta \psi \mathrm{m}$ is increased in $\mathrm{MPP}^{+}$infected MES23.5 cells after SP incubation for $24 \mathrm{~h}$. The fluorometric assay of the (A) control group, (B) MPP ${ }^{+}$group, (C) $\mathrm{SP}+\mathrm{MPP}^{+}$group and (D) $\mathrm{SR}+\mathrm{SP}+\mathrm{MPP}^{+}$group. (E) Statistical analysis of the data. $\Delta \psi \mathrm{m}$ was decreased in $\mathrm{MPP}^{+}$and $\mathrm{SR}+\mathrm{SP}+\mathrm{MPP}^{+}$groups compared with the control and increased in the $\mathrm{SP}+\mathrm{MPP}^{+}$group compared with the $\mathrm{MPP}^{+}$group. Data are expressed as the mean \pm standard error of the mean of 6 independent experiments. " $\mathrm{P}<0.05$, compared with the control. ${ }^{\prime} \mathrm{P}<0.05$, compared with the MPP ${ }^{+}$group. $\Delta \psi \mathrm{m}$, mitochondrial membrane potential; MPP ${ }^{+}$, 1-methyl-4-phenylpyridinium; SP, substance P; SR, NK-1 receptor inhibitor.

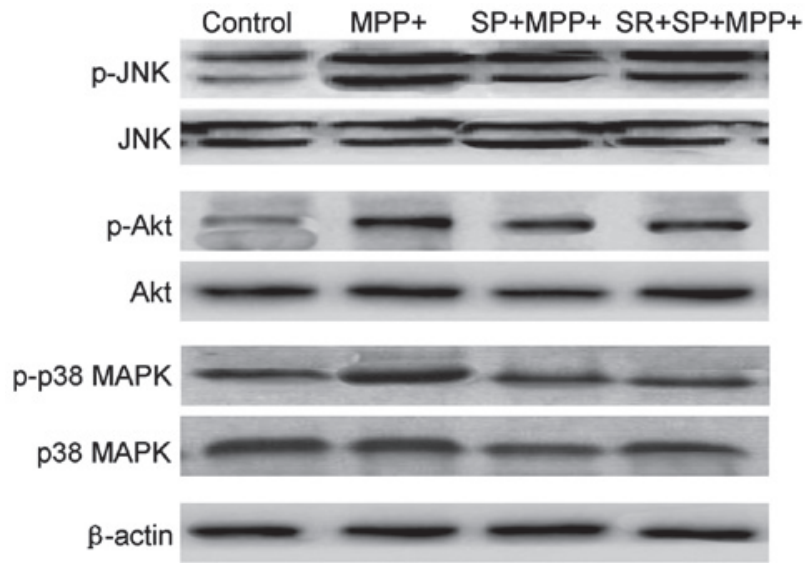

Figure 7. Effects of SP on phosphorylation of JNK, p38 and Akt in MES23.5 cells. MPP+, 1-methyl-4-phenylpyridinium; SP, substance P; SR, NK-1 receptor inhibitor; MAPK, mitogen-activated protein kinase; JNK, c-Jun $\mathrm{N}$-terminal kinase.

measurement result indicates that $\mathrm{MPP}^{+}$treatment promoted $\mathrm{Ca}^{2+}$ influx in the cultured MES23.5 cells. However, treatment with SP significantly decreased $\mathrm{Ca}^{2+}$ influx (Fig. 4).

SP decreases ROS production in MPP'-treated MES23.5 cells. ROS are critical in cell apoptosis, therefore, intracellular ROS levels were detected using a fluorescence sensitive probe, $\mathrm{H}_{2}$ DCFDA, which was used to examine numerous active oxygen species in MES23.5 cells (Fig. 5). The results indicate that the ROS production in the $\mathrm{MPP}^{+}$group was significantly increased compared with the control group (Fig. 5; P<0.05). The SP treatment appeared to significantly decrease the ROS production of the $\mathrm{MPP}^{+}$group (Fig. 5), as the ROS production in the $\mathrm{SP}+\mathrm{MPP}^{+}$group was significantly deceased when compared with the $\mathrm{MPP}^{+}$group $(\mathrm{P}<0.05)$. However, treatment with the SR may have abrogated the effects of SP treatment (Fig. 5).

SP decreases $\triangle \psi m$ in MPP'-treated MES23.5 cells. During apoptosis, the $\Delta \psi \mathrm{m}$ is associated with apoptosis and represents mitochondrial function. Therefore, the $\Delta \psi \mathrm{m}$ was examined in MPP+treated MES23.5 cells (Fig. 6). The results indicate that the $\Delta \psi \mathrm{m}$ in the $\mathrm{MPP}^{+}$group was significantly increased when compared with the control group (Fig. 6; $\mathrm{P}<0.05$ ). The SP treatment may also significantly decrease the $\Delta \psi \mathrm{m}$ of the $\mathrm{MPP}^{+}$group (Fig. 6). Furthermore, the $\Delta \psi \mathrm{m}$ in the $\mathrm{SP}+\mathrm{MPP}^{+}$ group was significantly deceased when compared with the $\mathrm{MPP}^{+}$group $(\mathrm{P}<0.05)$. However, treatment with the SR may have abrogated the effects of SP treatment (Fig. 6).

SP inhibits the $M M P^{+}$-induced phosphorylation of JNK, $p 38$ MAPK and Akt. Fig. 7 demonstrates that $\mathrm{MMP}^{+}$treatment may lead to a marginal increase in the phosphorylation of JNK, p38 MAPK and Akt in MES23.5 cells without altering the total level of the above three proteins. However, treatment with SP significantly inhibited the activation, also termed phosphorylation, of p38 MAPK, JNK and Akt protein (Fig. 7). The present results also revealed that SP treatment could regulate the activation of JNK, p38 and Akt protein in $\mathrm{MMP}^{+}$-injured MES23.5 cells.

\section{Discussion}

Previous studies have reported that SP is critical in PD pathophysiology $(12,15,16)$. However, the mechanism underlying the function of SP-induced neuroprotection in PD remains elusive. A previous study only demonstrated the neural growth function of SP (27). The present study indicated the neuroprotective 
function of SP in the $\mathrm{MPP}^{+}$-treated MES23.5 cells, and further examined the underlying mechanism of this effect. The present study demonstrated that SP may inhibit the $\mathrm{MPP}^{+}$-triggered neurotoxicity through inhibiting cell apoptosis via the NK-1 receptor in MES23.5 cells. Furthermore, the neuroprotective effects of SP were achieved by regulating the $\Delta \psi \mathrm{m}$, changing the calcium influx, and modulating the ROS production and caspase- 3 activation.

In the present study, the MES23.5 cell line was selected mainly due to evidence suggesting that it contains certain neuronal characteristics, including a dopamine synthesis system, tyrosine hydroxylase and expression of the $\omega$-conotoxin receptor (28). The above characteristics are similar to the features of primary neurons. Therefore, the results obtained from this cell line may be used to represent the degenerated neurons in PD.

$\mathrm{MPP}^{+}$is a common type of neurotoxic agent used to establish models of $\mathrm{PD}$. $\mathrm{MPP}^{+}$may be transduced into the cell via the cells dopamine re-uptake system. Subsequently, $\mathrm{MPP}^{+}$is able to inhibit the formation of complex I in the mitochondrial respiratory chain, which may trigger dopaminergic neurodegeneration (29).

The etiology of PD remains to be fully determined. Apoptosis-associated neuronal death has only been described in a few patients with PD (30). Consistent with the previous study (30), the morphological data obtained in the present study demonstrated that dopaminergic cell death indeed occurs by triggering apoptosis in a model of PD.

Increasing numbers of studies have clearly demonstrated the function of apoptosis in neuronal death and neurodegeneration of dopaminergic neurons in patients with PD $(31,32)$. These studies have also indicated the critical role of the caspase family of cysteine proteases in apoptosis. These enzymes are involved in the cascade, which is triggered in response to pro-apoptotic signals and culminates in the cleavage of a set of proteins (33). In the present study, the occurrence of apoptosis was evaluated by examining caspase- 3 activation (cleaved caspase-3 protein).

There are multiple studies demonstrating that ROS are involved in neurodegenerative diseases, such as AD and PD (23,26,30,31). Certain studies have also illustrated that the ROS could lead to cell death via the activation of the cell apoptosis signaling pathway $(26,30)$. In the present study, the results indicated that $\mathrm{MPP}^{+}$treatment could induce an increased level of ROS in MES23.5 cells. However, this increase in ROS could be blocked by pretreatment with SP. These results suggest that the anti-apoptotic effects of SP on $\mathrm{MPP}^{+}$-treated MES23.5 cells were achieved by triggering the mitochondrial pathway.

In addition, CNS tissues have been analyzed (which were derived from patients with PD, Huntington's disease and amyotrophic lateral sclerosis) in order to examine the role of cellular $\mathrm{Ca}^{2+}$ in the neurons. The results indicated that the cellular $\mathrm{Ca}^{2+}$ overload is the direct cause for the death of vulnerable neurons in the aforementioned diseases $(24,30)$. Beal (34) demonstrated that excessive $\mathrm{Ca}^{2+}$-mediated nitric oxide production contributes to the death of dopaminergic neurons in PD (34). Furthermore, $\mathrm{Ca}^{2+}$ is also one of the most critical signaling molecules in mammalian cells. $\mathrm{Ca}^{2+}$ may also regulate the diverse cellular functions of cells (35). Therefore, the rise of intracellular $\mathrm{Ca}^{2+}$ may trigger neuronal cell death or apoptosis in PD (36). The association between $\left[\mathrm{Ca}^{2+}\right]_{\mathrm{er}}$ and cell death is rather complex.
There is a substantial body of data demonstrating that reducing $\left[\mathrm{Ca}^{2+}\right]_{\mathrm{er}}$ has a protective effect against apoptosis, dependent on stimuli releasing $\mathrm{Ca}^{2+}$ from intracellular stores (37).

The JNK signaling pathway is a major transduction pathway, which may mediate apoptotic cell death, or even neuronal degeneration in response to numerous cellular stimuli (38). JNK is a member of a subfamily of the MAPK superfamily. JNK acts as a pro-apoptotic kinase in the apoptotic processes, including the extrinsic apoptotic pathway and the intrinsic apoptotic pathways. Therefore, JNK activates the apoptotic signaling pathway by upregulating the pro-apoptotic proteins. The regulation was completed by phosphorylating specific transcription factors, such as ATF2, c-Jun, p53, Elk-1 and c-Myc. In addition, JNK could also modulate the activities of anti- and pro-apoptotic proteins directly, such as B-cell lymphoma 2 and $\mathrm{Bcl}-2$-associated X protein (39). SP600125 is a common JNK inhibitor, which could inhibit the phosphorylation of c-Jun and protect against transient ischemia/reperfusion-triggered neuronal death or apoptosis in the hippocampal CA1 region of the rat. SP600125, at a concentration of $2-10 \mu \mathrm{M}$, may markedly protected the cortical neurons from glutamate toxicity (40). In the present study, the results indicated that SP inhibited the activation of JNK in $\mathrm{MPP}^{+}$-injured MES23.5 cells. However, SP also fails to rescue the glutamate-injured hippocampal neurons from cell apoptosis in the presence of SP600125. A previous study revealed that SP600125 is able to regulate Akt phosphorylation when serum and potassium were withdrawn in the cerebellar granule cells (41). However, in the present $\mathrm{MPP}^{+}$injury model of PD, the results indicated that the SP600125-induced JNK inhibition could not activate the Akt protein (data not shown). Therefore, this phenomenon also requires further clarification.

P38 is another important member of the MAPK protein family, which may be activated in response to glutamate stimulation of the N-methyl-D-aspartate receptors (42). SB203580 is a type of p38MAPK-specific inhibitor, which may prevent glutamate-induced neuronal death and apoptosis in cultured cortical neurons (43). In the present study, the results revealed that $\mathrm{MPP}^{+}$could detectably stimulate the phosphorylation of p38 in MES23.5 cells. In addition, SP may affect p38 activation, which indicates that $\mathrm{p} 38$ is involved in the neuroprotective function of SP in the MPP+-injured MES23.5 cells.

In conclusion, the present study demonstrated the antioxidant effects of SP against $\mathrm{MPP}^{+}$-induced cell death and apoptosis, by decreasing calcium influx, increasing the $\Delta \psi \mathrm{m}$, reducing the ROS production and inhibiting caspase-3 activation. The phosphorylation of the p38 protein and JNK protein signaling pathways were regulated by treatment with SP. The SP-activated p38 and JNK signaling pathway promoted the cell viability and survival of cells. For clinical therapy, SP may be developed as a potential drug for treating neuronal cell damage and neurodegenerative disorders, based on its neuroprotective function.

\section{Acknowledgements}

The authors would like to thank Dr Wei-Dong Le (Qingdao University, Qingdao, China) for providing the MES23.5 cell line and thank Sanofi-Aventis (Chilly-Mazarin, France) for providing the SR140333B. This study was supported by a 
grant from the National Natural Science Foundation of China (grant nos. 31070942 and 81200872) and the Doctoral Fund of Ministry of Education of China (grant no. 20123706110001).

\section{References}

1. Li DW, Liu ZQ, Chen W, Yao M and Li GR: Association of glycogen synthase kinase-3 $\beta$ with Parkinson's disease (review). Mol Med Rep 9: 2043-2050, 2014.

2. Obeso JA, Rodríguez-Oroz MC, Rodríguez M, Lanciego JL, Artieda J, Gonzalo N and Olanow CW: Pathophysiology of the basal ganglia in Parkinson's disease. Trends Neurosci 23 (Suppl): S8-S19, 2000.

3. Oertel WH and Ellgring H: Parkinson's disease - medical education and psychosocial aspects. Patient Educ Couns 26: 71-79, 1995.

4. Levy OA, Malagelada C and Greene LA: Cell death pathways in Parkinson's disease: Proximal triggers, distal effectors, and final steps. Apoptosis 14: 478-500, 2009.

5. Irrcher I and Park DS: Parkinson's disease: To live or die by autophagy. Sci Signal 2: pe21, 2009.

6. Hartmann A and Hirsch EC: Parkinson's disease. The apoptosis hypothesis revisited. Adv Neurol 86: 143-153, 2001.

7. Tatton WG, Chalmers-Redman R, Brown D and Tatton N: Apoptosis in Parkinson's disease: Signals for neuronal degradation. Ann Neurol 53 (Suppl 3): S61-S72, 2003.

8. Chang WA, Lin ES, Tsai MJ, Huang MS and Kuo PL: Isolinderalactone inhibits proliferation of A549 human non small cell lung cancer cells by arresting the cell cycle at the G0/G1 phase and inducing a Fas receptor and soluble Fas ligand-mediated apoptotic pathway. Mol Med Rep 9: 1653-1659, 2014.

9. Anglade P, Vyas S, Javoy-Agid F, Herrero MT, Michel PP, Marquez J, Mouatt-Prigent A, Ruberg M, Hirsch EC and Agid Y: Apoptosis and autophagy in nigral neurons of patients with Parkinson's disease. Histol Histopathol 12: 25-31, 1997.

10. Fornai F, Lenzi P, Gesi M, Soldani P, Ferrucci M, Lazzeri G Capobianco L, Battaglia G, De Blasi A, Nicoletti F, et al: Methamphetamine produces neuronal inclusions in the nigrostriatal system and in PC12 cells. J Neurochem 88: 114-123, 2004

11. Yakhine-Diop SM, Bravo-San Pedro JM, Gómez-Sánchez R, Pizarro-Estrella E, Rodríguez-Arribas M, Climent V, Aiastui A, López de Munain A, Fuentes JM and González-Polo RA: G2019S LRRK2 mutant fibroblasts from Parkinson's disease patients show increased sensitivity to neurotoxin 1-methyl-4-phenylpyridinium dependent of autophagy. Toxicology 324: 1-9, 2014.

12. Robinson P, Garza A, Moore J, Eckols TK, Parti S, Balaji V, Vallejo J and Tweardy DJ: Substance P is required for the pathogenesis of EMCV infection in mice. Int J Clin Exp Med 2: 76-86, 2009.

13. Barker R: Tachykinins, neurotrophism and neurodegenerative diseases: A critical review on the possible role of tachykinins in the aetiology of CNS diseases. Rev Neurosci 7: 187-214, 1996.

14. Thornton E and Vink R: Treatment with a substance P receptor antagonist is neuroprotective in the intrastriatal 6-hydroxydopamine model of early Parkinson's disease. PLoS One 7: e34138, 2012.

15. Nalivaiko E, Michaud JC, Soubrié P, Le Fur G and Feltz P: Tachykinin neurokinin-1 and neurokinin-3 receptor-mediated responses in guinea-pig substantia nigra: An in vitro electrophysiological study. Neuroscience 78: 745-757, 1997.

16. Strell C, Sievers A, Bastian P, Lang K, Niggemann B, Zänker KS and Entschladen F: Divergent effects of norepinephrine dopamine and substance $\mathrm{P}$ on the activation, differentiation and effector functions of human cytotoxic T lymphocytes. BMC Immunol 10: 62, 2009.

17. Crawford GD Jr, Le WD, Smith RG, Xie WJ, Stefani E and Appel SH: A novel N18TG2 x mesencephalon cell hybrid expresses properties that suggest a dopaminergic cell line of substantia nigra origin. J Neurosci 12: 3392-3398, 1992.

18. Liu L, Xu H, Jiang H, Wang J, Song N and Xie J: Ghrelin prevents 1-methyl-4-phenylpyridinium ion-induced cytotoxicity through antioxidation and NF-kappaB modulation in MES23.5 cells. Exp Neurol 222: 25-29, 2010.

19. Yao G, Yang L, Hu Y, Liang J, Liang J and Hou Y: Nonylphenol-induced thymocyte apoptosis involved caspase-3 activation and mitochondrial depolarization. Mol Immunol 43 : 915-926, 2006

20. Feng Z and Zhang JT: Protective effect of melatonin on b-amyloid induced apoptosis in rat astroglioma c6 cells and its mechanism. Free Radic Biol Med 2004: 1790-1801, 2014
21. Wei CD, Li Y, Zheng HY, Tong YQ and Dai W: Palmitate induces $\mathrm{H} 9 \mathrm{c} 2$ cell apoptosis by increasing reactive oxygen species generation and activation of the ERK1/2 signaling pathway. Mol Med Rep 7: 855-861, 2013.

22. Zhao L, Teng B, Wen L, Feng Q, Wang H, Li N, Wang Y and Liang Z: mTOR inhibitor AZD8055 inhibits proliferation and induces apoptosis in laryngeal carcinoma. Int J Clin Exp Med 7: 337-347, 2014.

23. Egnatchik RA, Leamy AK, Jacobson DA, Shiota M and Young JD: ER calcium release promotes mitochondrial dysfunction and hepatic cell lipotoxicity in response to palmitate overload. Mol Metab 3: 544-553, 2014.

24. Wang XJ and Xu JX: Possible involvement of $\mathrm{Ca}^{2+}$ signaling in rotenone-induced apoptosis in human neuroblastoma SH-SY5Y cells. Neurosci Lett 376: 127-132, 2005.

25. Bhattacharyya S, Ghosh S, Shant J, Ganguly NK and Majumdar S: Role of the W07-toxin on Vibrio cholerae-induced diarrhoea. Biochim Biophys Acta 1670: 69-80, 2004.

26. Wang J, Du XX, Jiang H and Xie JX: Curcumin attenuates 6-hydroxydopamine-induced cytotoxicity by anti-oxidation and nuclear factor-kappa B modulation in MES23.5 cells. Biochem Pharmacol 78: 178-183, 2009.

27. Iwasaki Y, Kinoshita M, Ikeda K, Takamiya K and Shiojima T: Trophic effect of various neuropeptides on the cultured ventral spinal cord of rat embryo. Neurosci Lett 101: 316-320, 1989.

28. Bleiblo F, Michael P, Brabant D, Ramana CV, Tai T, Saleh M, Parrillo JE, Kumar A and Kumar A: JAK kinases are required for the bacterial RNA and poly I:C induced tyrosine phosphorylation of PKR. Int J Clin Exp Med 6: 16-25, 2013.

29. Kitamura Y, Shimohama S, Akaike A and Taniguchi T: The parkinsonian models: Invertebrates to mammals. Jpn J Pharmacol 84: 237-243, 2000.

30. Siddique YH, Naz F and Jyoti S: Effect of curcumin on lifespan, activity pattern, oxidative stress, and apoptosis in the brains of transgenic Drosophila model of Parkinson's disease. BioMed Res Int 606928: 2014, 2014.

31. Zhang Z, Zhang K, Du X and Li Y: Neuroprotection of desferrioxamine in lipopolysaccharide-induced nigrostriatal dopamine neuron degeneration. Mol Med Rep 5: 562-566, 2012.

32. Ekshyyan O and Aw TY: Apoptosis: A key in neurodegenerative disorders. Curr Neurovasc Res 1: 355-371, 2004.

33. Enari M, Sakahira H, Yokoyama H, Okawa K, Iwamatsu A and Nagata S: A caspase-activated DNase that degrades DNA during apoptosis, and its inhibitor ICAD. Nature 391: 43-50, 1998.

34. Beal MF: Excitotoxicity and nitric oxide in Parkinson's disease pathogenesis. Ann Neurol 44 (Suppl 1): S110-S114, 1998.

35. Ma S, Cai C, Ma Y, Bai Z, Meng X, Yang X, Zou F and Ge R: Store-operated $\mathrm{Ca}^{2+}$ entry mediated regulation of polarization in differentiated human neutrophil-like HL-60 cells under hypoxia. Mol Med Rep 9: 819-824, 2014

36. Kim HY, LaVaute T, Iwai K, Klausner RD and Rouault TA: Identification of a conserved and functional iron-responsive element in the 5'-untranslated region of mammalian mitochondrial aconitase. J Biol Chem 271: 24226-24230, 1996.

37. Scorrano L, Oakes SA, Opferman JT, Cheng EH, Sorcinelli MD, Pozzan T and Korsmeyer SJ: BAX and BAK regulation of endoplasmic reticulum $\mathrm{Ca}^{2+}$ : A control point for apoptosis. Science 300: 135-139, 2003.

38. Brecht S, Kirchhof R, Chromik A, Willesen M, Nicolaus T, Raivich G, Wessig J, Waetzig V, Goetz M, Claussen M, et al: Specific pathophysiological functions of JNK isoforms in the brain. Eur J Neurosci 21: 363-377, 2005.

39. Dhanasekaran DN and Reddy EP: JNK signaling in apoptosis. Oncogene 27: 6245-6251, 2008.

40. Eminel S, Roemer L, Waetzig V and Herdegen T: c-Jun N-terminal kinases trigger both degeneration and neurite outgrowth in primary hippocampal and cortical neurons. J Neurochem 104: 957-969, 2008

41. Yeste-Velasco M, Folch J, Casadesús G, Smith MA, Pallàs M and Camins A: Neuroprotection by c-Jun NH2-terminal kinase inhibitor SP600125 against potassium deprivation-induced apoptosis involves the Akt pathway and inhibition of cell cycle reentry. Neuroscience 159: 1135-1147, 2009.

42. Hsu MJ,Hsu CY, Chen BC, Chen MC, Ou G and Lin CH: Apoptosis signal-regulating kinase 1 in amyloid beta peptide-induced cerebral endothelial cell apoptosis. J Neurosci 27: 5719-5729, 2007.

43. Liu XW, Ji EF, He P, Xing RX, Tian BX and Li XD: Protective effects of the p38 MAPK inhibitor SB203580 on NMDA induced injury in primary cerebral cortical neurons. Mol Med Rep 10: 1942-1948, 2014 